Slavica

bruxellensia

\section{Slavica bruxellensia}

Revue polyphonique de littérature, culture et histoire

slaves

$6 \mid 2010$

Linguistique russe

\title{
Ellen Rutten, Unattainable Bride Russia - Gendering Nation, State, and Intelligentsia in Russian Intellectual Culture
}

\section{Elise Hanut}

\section{(2) OpenEdition}

Journals

\section{Édition électronique}

URL : http://journals.openedition.org/slavica/360

DOI : $10.4000 /$ slavica.360

ISSN : 2034-6395

Éditeur

Université libre de Bruxelles - ULB

\section{Édition imprimée}

Pagination : 68-70

ISSN : 2037-7654

Référence électronique

Elise Hanut, «Ellen Rutten, Unattainable Bride Russia - Gendering Nation, State, and Intelligentsia in Russian Intellectual Culture », Slavica bruxellensia [En ligne], 6 | 2010, mis en ligne le 15 juin 2010, consulté le 21 septembre 2020. URL : http://journals.openedition.org/slavica/360 ; DOI : https:// doi.org/10.4000/slavica.360

Ce document a été généré automatiquement le 21 septembre 2020.

\section{(c) (i) (9)}

Les contenus de Slavica bruxellensia sont mis à disposition selon les termes de la Licence Creative Commons Attribution - Pas d'Utilisation Commerciale - Pas de Modification 3.0 France. 


\section{Ellen Rutten, Unattainable Bride} Russia - Gendering Nation, State, and Intelligentsia in Russian Intellectual Culture

Elise Hanut

\section{RÉFÉRENCE}

Ellen Rutten, Unattainable Bride Russia - Gendering Nation, State, and Intelligentsia in Russian Intellectual Culture, Illinois, Northwestern University Press, 2010, 328 p. 
1 Dans cet ouvrage, Ellen Rutten nous guide à travers la littérature russe de la fin du $\mathrm{XIX}^{\mathrm{e}}$ siècle à nos jours à la recherche de la représentation allégorique de la Russie en tant que femme séduisante et, en ses termes, en tant « qu'épouse inaccessible ». En effet, à partir de la fin du XIX ${ }^{\mathrm{e}}$ siècle, les auteurs russes commencèrent à décrire la Russie en des termes féminins et utilisèrent fréquemment la métaphore de la femme-Russie. De nombreuses œuvres à ce sujet ont bien sûr déjà vu le jour, mais une approche globale sur le thème manquait. Notons d'emblée que la lecture de Unattainable Bride Russia n'est pas destiné aux néophytes, une solide connaissance de l'histoire littéraire russe est requise, compte tenu des nombreuses références intertextuelles. Rutten décortique minutieusement un impressionnant nombre d'œuvres pour

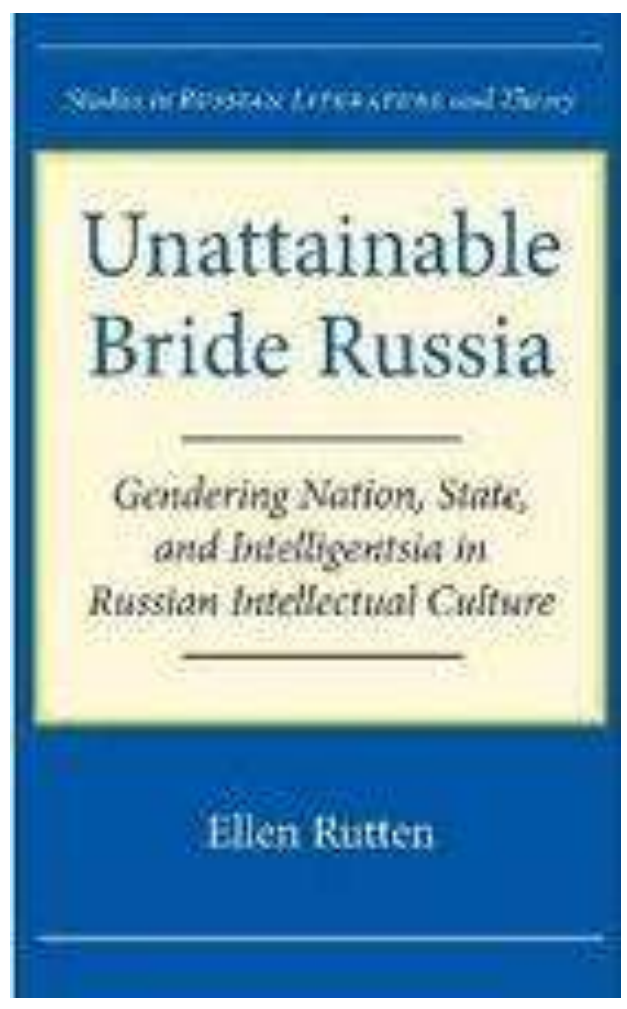
montrer le processus de changement qu'a connu la métaphore en un espace de cent ans. Dans un anglais recherché et raffiné, Rutten expose un des mythes culturels les plus exploités.

2 La femme-Russie devient l'objet de tous les désirs dans un triangle amoureux entre elle-même, l'intelligentsia et le pouvoir. Dans la vision de Rutten, les intellectuels d'une part et le pouvoir, soit-il tsariste, soviétique ou étranger, d'autre part, convoitent en tant que personnage masculin, la Russie. La relation reste cependant stérile, ce qui trouve ses origines dans le contexte socio-politique et culturel du tsarisme. Rutten se focalise surtout sur le rôle métaphorique que joue l'intelligentsia en tant qu'époux rejeté ou impuissant.

3 Le voyage littéraire commence par le symboliste Aleksandr Blok qui, par son immense influence, sert de fil conducteur tout au long de l'étude. Les poètes Andrej Belyj et Nikolaj Berdjaev constituent également une source d'inspiration à la métaphore. Blok, héritier de la tradition littéraire du XIX ${ }^{\mathrm{e}}$ siècle, lui même issu de la noblesse russe ayant profité d'une éducation à l'européenne, ressentit une dissociation entre l'intelligentsia et la classe ouvrière. Ses lettres, fragments de journal intime, pièces de théâtre, essais et poèmes démontrent qu'à travers ses héros il souffrait de cette distance qui séparait la Russie du peuple. L'utilisation de la métaphore n'était rien d'autre qu'une manière d'aborder les thématiques qui animaient les auteurs de l'époque.

Avec l'avènement de l'époque soviétique, la métaphore est moins présente. Dans son discours politique, la Russie n'est désormais plus représentée comme une Belle au Bois Dormant qui veut être secourue par son prince charmant, mais bien en tant que mère soviétique, personnage féminin fort. Pour démontrer que la métaphore romantique est toujours bien vivante, Rutten évoque Le Docteur Jivago de Boris Pasternak. De façon convaincante, elle démontre que l'héroïne Lara n'est autre qu'une allégorie de la Russie, que le personnage Komarovski est la représentation du mal qui empêche le 
protagoniste, le docteur Jivago, de retrouver sa bien-aimée. Le triangle amoureux se voit ainsi parfaitement illustré.

Dans un dernier chapitre, Rutten nous prouve que les auteurs postmodernes utilisent toujours cette même métaphore de l'épouse bien que sous une tout autre forme, cette fois cynique et ironique. La métaphore est revenue en force, non plus comme idéal politique, mais comme cliché culturel et littéraire. La représentation de la Russie n'est plus abstraite, mais absolument physique. L'épouse n'est plus convoitée et admiré à distance, mais brutalisée et abusée. Bien que les auteurs Venedikt Erofeev et Vladimir Sorokin prétendent être indifférents aux métaphores, Rutten démontre par de nombreux exemples textuels, que l'image de l'épouse Russie est en fait central dans leurs œuvres.

Rutten démontre que la métaphore est toujours aussi puissante dans l'art contemporain, et nous cite d'ailleurs des exemples de réalisations visuelles qui pointent la tension entre le régime politique en place et la Russie du peuple.

Il est encore à noter que bien que la littérature constitue le point de départ de l'étude de Rutten, celle-ci évoque également des œuvres d'art, des articles journalistiques ou pièces de théâtre pour illustrer la métaphore, ce qui rend son travail légèrement plus accessible. Le texte reste par moments lourd par l'utilisation abondante d'exemples, de citations et de références entre guillemets.

Dans cet ouvrage, Rutten révèle sans aucun doute que, de façon souvent dissimulée, la Russie est le centre d'intérêt de nombreuses œuvres littéraires. De façon claire et ordonnée, l'auteur nous dévoile les tendances littéraires récurrentes. Unattainable Bride Russia impose la relecture des grands classiques russes sous un oeil critique. Les héroïnes ne peuvent plus être perçues uniquement comme des représentations de femmes russes, mais également comme des représentations de la Russie même.

\section{INDEX}

Mots-clés : histoire de la Russie, littérature russe

Index chronologique : XIXe siècle, XXe siècle

\section{AUTEURS}

\section{ELISE HANUT}

Étudiante à l'Université Libre de Bruxelles en Langues et Littératures slaves 